\title{
Development of Hot-wire Laser Welding Method for Lap Joint of Steel Sheet with Wide Gap*
}

\author{
by Motomichi Yamamoto **, Kenji Shinozaki **, Kota Kadoi **, Daigo Fujita ***, Takeshi Inoue **, \\ Mitsugu Fukahori**** and Yoichiro Kitahara ****
}

\begin{abstract}
In this study, hot-wire laser welding was used to develop the welding method for the lap joint of 980MPa class high-strength steel sheets (thickness: $1 \mathrm{~mm}$ ) with a wide gap. Detailed phenomena of wire melting and bead formation during welding were understood using the high-speed camera, and then the optimum welding condition and the mechanical properties of weld joints were investigated. The fiber laser with hot wire was used for welding the lap joint with the gap of $1 \mathrm{~mm}$. The welding parameters such as the laser output of $3 \mathrm{~kW}$, spot diameter of $1.5 \mathrm{~mm} \phi$, welding speed of $1.5 \mathrm{~m} / \mathrm{min}$ and the wire feeding speed of $3.8 \mathrm{~m} / \mathrm{min}$ were fixed. The welding parameters of hot wire such as wire insertion angle, wire insertion position, and current of wire were varied. Moreover, shear test of the weld joints were done. As a result, upper and lower sheets with gap of $1 \mathrm{~mm}$ were well joined without weld defects in the welding parameters such as the wire insertion positions (from the laser spot center) of $3 \mathrm{~mm}$ and the wire insertion angle of $70^{\circ}$ and the wire currents of 102 116A. Moreover, the tensile shear strengths of weld joints were 500 600MPa regardless of the wire current.
\end{abstract}

Key Words: Laser welding, Hot-wire, Lap joint, Wide gap, high-strength steel

\section{Introduction}

There has been recent, the use of high strength / ultra-high strength steel sheets for an automobile body is widely investigated since the strong demand to reduce automobile body weight and energy consumption is increasing rapidly, moreover lap joints of high strength / ultra-high strength steel sheets by using laser welding for body construction is investigated to improve the body stiffness ${ }^{1 \sim 7)}$. However it is difficult to predict and control precisely springback behavior during press forming of high strength / ultra-high strength steel sheets, then a large gap between lapped sheets is created. In general, laser welding has only small gap tolerance and the laser welding speed with a filler wire to fill the gap must decrease.

Hot-wire GTA welding has been developed to improve the deposition rate through energization of the filler wire ${ }^{8)}$. Shinozaki and Yamamoto et al. developed ultra-high-speed Gas Tungsten Arc (GTA) welding based on the above hot-wire system ${ }^{9 \sim 11)}$. In their studies, the basic effects of different welding parameters on the welding phenomenon under the ultra-high welding speed condition have been obtained, and welding speeds up to $7 \mathrm{~m} / \mathrm{min}$ under the bead-on- plate condition and $5 \mathrm{~m} / \mathrm{min}$ under the fillet welding condition have been achieved.

In this study, the new laser welding process, which has a high

\footnotetext{
${ }^{*}$ Received: 2010.11 .12

${ }^{* *}$ Member, Graduate school of Engineering, Hiroshima University

${ }^{* * *}$ Member, Tsuneishi Shipbuilding Company, Tsuneishi Holdings Corporation

${ }^{* * *}$ Member, Technical Research Center, Mazda Motor Corporation
}

welding speed with feeding a filler wire and large gap tolerance, is proposed and investigated by combining laser welding and the hot-wire system which has the ability to control filler wire melting independently from the main heat input.

\section{Experimental procedure}

$980 \mathrm{MPa}$ class steel sheets (JIS-G3135-SPFCY, t: $1 \mathrm{~mm}$ ) and a $590 \mathrm{MPa}$ class filler wire (JIS-Z3312 YGW23, $\phi 1.2 \mathrm{~mm}$ ) were used. $200 \mathrm{~mm}$ long and $50 \mathrm{~mm}$ wide specimens were used for basic investigation (see Fig. 1(a)), and $220 \mathrm{~mm}$ long and $100 \mathrm{~mm}$ wide specimens with a $30 \mathrm{~mm}$ lapped region were used for tensile tests (see Fig. 1(b)). A gap between lapped sheets was fixed as 1 $\mathrm{mm}$ by inserting shim tapes. The weld bead length was $180 \mathrm{~mm}$ and tensile specimens having $30 \mathrm{~mm}$ width were cut out in the above welded lapped sheets.

Table 1 shows the welding conditions employed in this study. A $3 \mathrm{~kW}$ fiber laser oscillator, a laser head with a $400 \mathrm{~mm}$ focal length and a hot-wire heating system produced by Bab-Hitachi Industrial Co. were used. This hot-wire heating system uses pulsed current with a pulse frequency of $100 \mathrm{~Hz}$ in this study. The welding speed, the laser power, the filler wire feeding speed and the laser irradiation angle were fixed as $1.5 \mathrm{~m} / \mathrm{min}, 3 \mathrm{~kW}, 3.8$ $\mathrm{m} / \mathrm{min}$ and $5^{\circ}$ respectively. The laser spot diameter, the wire feeding angle, the wire feeding position and the wire current were changed as experimental parameters. Filler wire was fed from backward into a welding region.

The in-situ observation was carried out using a high-speed camera to investigate filler wire melting and weld bead creation during hot-wire laser welding. The observation and evaluation of 
the bead surface and the cross section, and the tensile test were performed after welding.

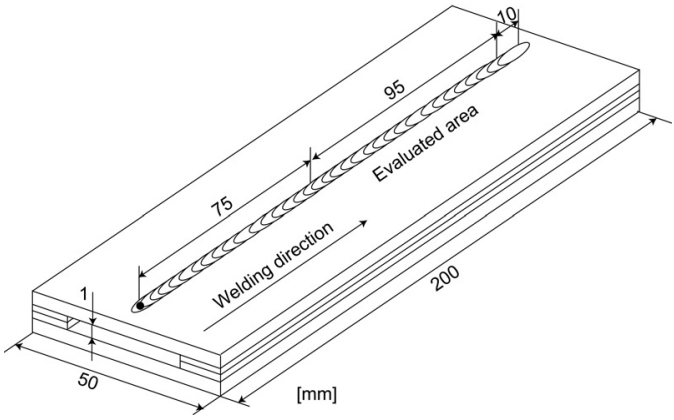

(a) Specimen for basic investigation.

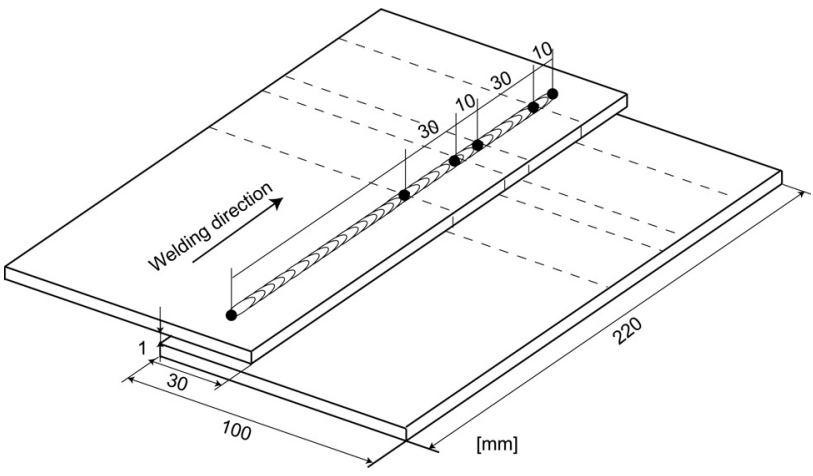

(b) Specimen for tensile test.

Fig. 1 Sizes and configurations of specimens.

Table 1 Welding conditions.

\begin{tabular}{|c|c|}
\hline Welding speed $(\mathrm{m} / \mathrm{min})$ & 1.5 \\
\hline Laser power $(\mathrm{kW})$ & 3 \\
\hline Laser spot size $(\mathrm{mm})$ & $1.2,1.5$ \\
\hline Wire feeding speed $(\mathrm{m} / \mathrm{min})$ & 3.8 \\
\hline Wire feeding angle $(\mathrm{deg})$ & $30 \sim 80$ \\
\hline Wire feeding position $(\mathrm{mm})$ & $0 \sim 6$ \\
\hline Wire current (R.M.S) $(\mathrm{A})$ & $98 \sim 120$ \\
\hline
\end{tabular}

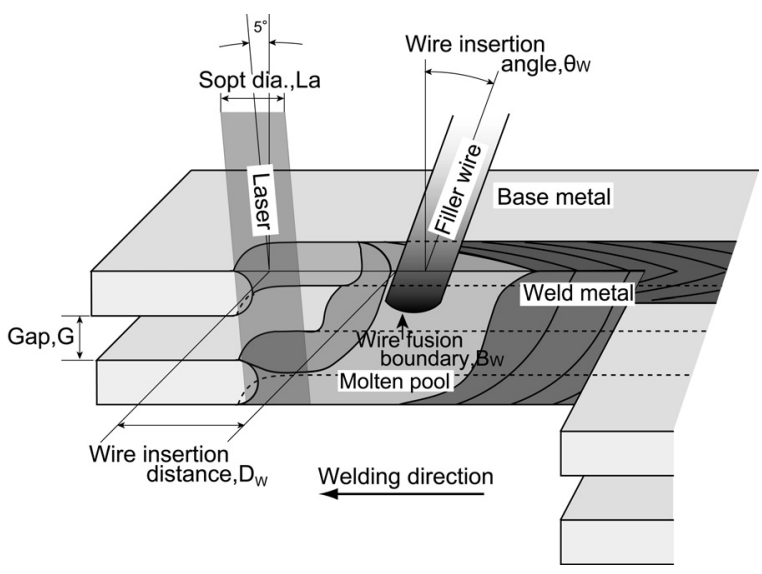

Fig. 2 Schematic illustration of hot-wire laser welding on lap joint with wide gap

\section{Result and discussion}

3.1 Concept of hot-wire laser welding for lap joint with wide gap

Figure 2 shows the schematic illustration of developed hot-wire laser welding on a lap joint with a wide gap. The penetrated hole initiates and weld metal does not fill the hole during laser welding without filler wire, then the sound bead and joint can't be created. Developed hot-wire laser welding can make stable wire feeding to fill the hole created by laser irradiation, and then the sound lap joint with a wide gap can be achieved by the proposed welding method. The following conditions are necessary to make stable filler wire feeding and the sound joint.

\subsection{Effect of spot diameter}

The suitable laser spot diameter and the welding speed which make the molten pool having a little lager width than the filler wire diameter are $1.5 \mathrm{~mm}$ and $1.5 \mathrm{~m} / \mathrm{min}$ respectively in this study under the $3 \mathrm{~kW}$ laser power condition. Figure 3 shows the cross sections when the laser spot diameter is $1.2 \mathrm{~mm}$ and $1.5 \mathrm{~mm}$. When the $1.2 \mathrm{~mm}$ spot diameter was employed, the penetrated width of the upper sheet was about $1 \mathrm{~mm}$ which was smaller than the filler wire diameter of $1.2 \mathrm{~mm}$, therefore the edge of filler wire touched and scratched the upper sheet, then the worse bead appearance was created. On the other hand, when the $1.5 \mathrm{~mm}$ spot diameter was employed, the penetrated width of the upper sheet was about $1.5 \mathrm{~mm}$ which was a little larger than the filler wire diameter of $1.2 \mathrm{~mm}$, therefore filler wire was fed smoothly into the penetrated hole, then the sound bead could be created.

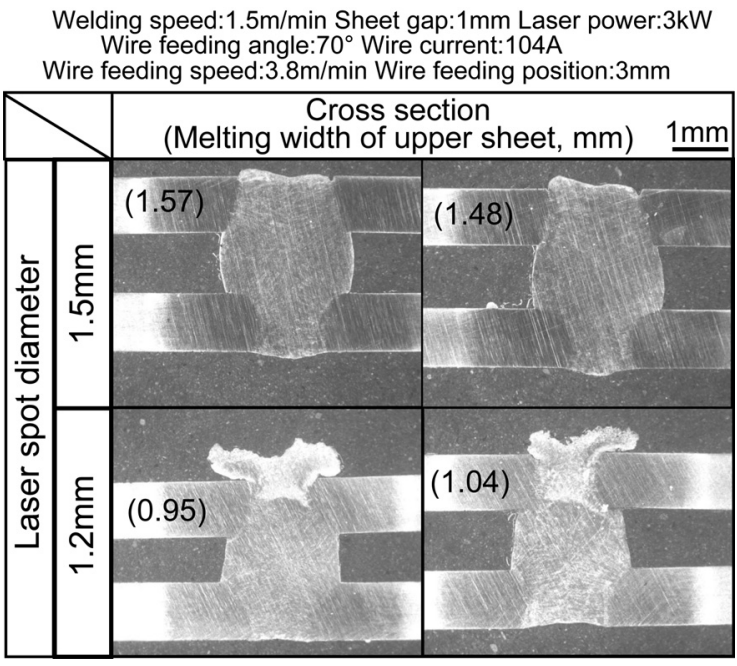

Fig. 3 Cross sections when laser spot diameter changes. 


\subsection{Effect of wire current}

Figure 4 shows the high-speed imaging output during hot-wire laser lap welding under the optimum welding condition. The adequate wire current which makes wire melting in the region from the upper sheet surface to the gap between the lapped sheets, $102 \sim 116$ A in this study.

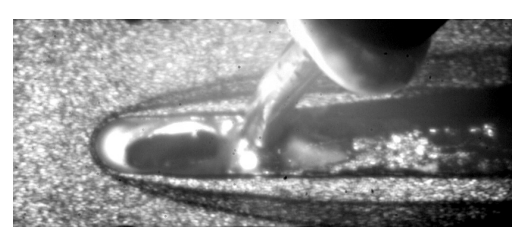

Fig. 4 High-speed imaging output during welding (optimum welding).

Figure 5 shows the cross-sections when the laser spot diameter is $1.5 \mathrm{~mm}$, the wire feeding angle is $70^{\circ}$, the wire feeding position is $3 \mathrm{~mm}$ and the wire current is varied. When the wire current was too low (under $100 \mathrm{~A}$ in this study), the lower sheet melting was unstable, then a hole defect on the upper sheet initiated or filler wire penetrated into the lower sheet. When the wire current was high (118 $120 \mathrm{~A}$ in this study), filler wire melted at the upper surface of the upper sheet, then the excess weld metal was formed but the serious defect was not created in the weld bead. When the wire current was too high (over $120 \mathrm{~A}$ in this study), filler wire was melted down before its tip reached the upper sheet surface, then the sound bead was not created. When the wire current was adequate $(102 \sim 116 \mathrm{~A}$ in this study), stable wire melting was achieved and the sound bead with the adequate cross-section and the surface appearance could be created.

\begin{tabular}{|l|l|l|l|l|}
\hline \multicolumn{2}{|c|}{$100 \mathrm{~A}$} & $110 \mathrm{~A}$ & $116 \mathrm{~A}$ & $120 \mathrm{~A}$ \\
\hline \hline 1 & & & & \\
\hline & & & & \\
\hline
\end{tabular}

Fig. 5 Cross-sections when wire current is varied.

\subsection{Effect of wire feeding position and feeding angle}

The adequate wire feeding position is the anterior region of the molten pool crated posterior to the penetrated hole.

Figure 6 shows the cross sections when the wire feeding position from the laser spot center is varied as $0 \sim 6 \mathrm{~mm}$, and the other optimum parameters are employed. When the wire feeding position is $3 \mathrm{~mm}$ from the laser spot center, filler wire tip is located at the molten pool just behind the penetrated hole, and it is fed into the penetrated hole stably, therefore the sound appearance and cross-section of the bead are obtained. When the wire feeding position is $6 \mathrm{~mm}$ from the laser spot center, filler wire tip is located at the solidifying region behind the molten pool, and it makes the scratch on the bead surface as shown in this figure. When the wire feeding position is $0 \mathrm{~mm}$ from the laser spot center, the laser beam irradiates on the filler wire tip directly, therefore the tip is melted down frequently. Although the bead appearance is good and enough weld metal and joint is created between the upper sheet and the lower sheet, filler wire melting is not steady.

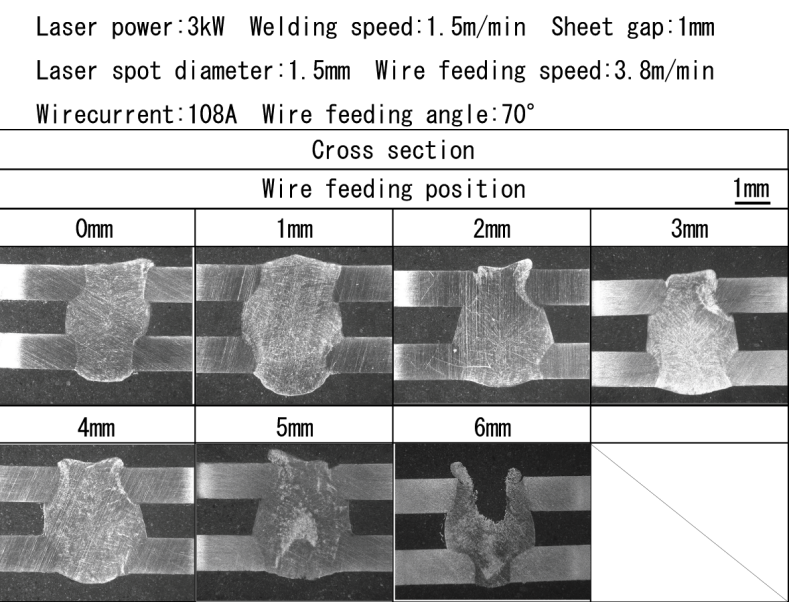

Fig. 6 Cross-sections when wire current is varied.

Figure 7 shows the effect of the wire feeding angle on the optimum wire current. When the wire feeding angle becomes too low $\left(30^{\circ}\right.$ and $50^{\circ}$ in this study), filler wire touches the upper sheet surface at the back of the molten pool, then stable wire feeding can not be performed. When the wire feeding angle is too high $\left(80^{\circ}\right.$ in this study), the filler wire tip melts down frequently since the reflected laser beam irradiated unsteadily on its surface. When the wire feeding angle is $70^{\circ}$ in this study, the filler wire tip touches stably the molten pool posterior to the penetrated hole, then the optimum wire current region becomes wider.

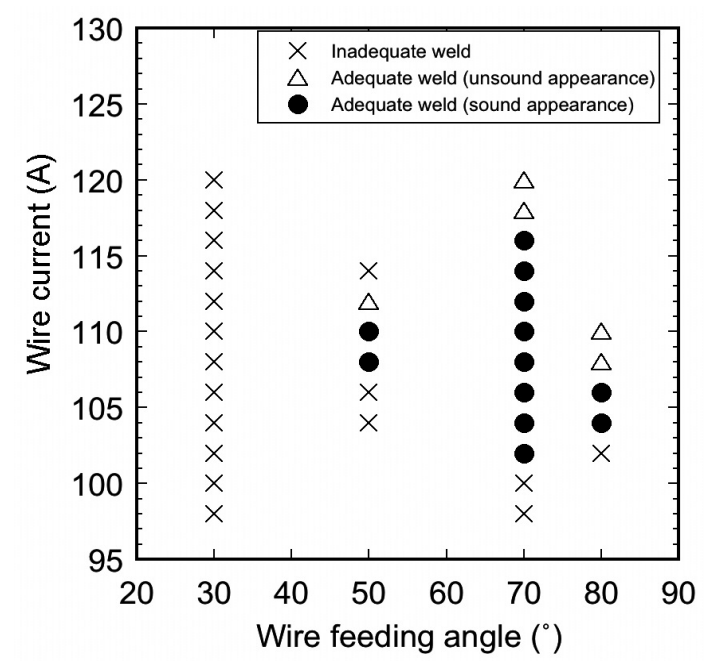

Fig. 7 Effect of wire feeding angle on optimum wire current. 
Figure 8 shows the tensile shear test result when the wire current is varied from $102 \mathrm{~A}$ to $120 \mathrm{~A}$. The laser spot diameter is $1.5 \mathrm{~mm}$, the wire feeding angle is $70^{\circ}$ and the wire feeding position is $3 \mathrm{~mm}$ based on the above investigations. The fracture path is in the base metal or the boundary between the base metal and the weld metal since the welded joint produced using the proposed hot-wire laser welding method has no serious defect in it. It is clear from the figure that the stable tensile shear strength can be obtained in the optimum wire current region.

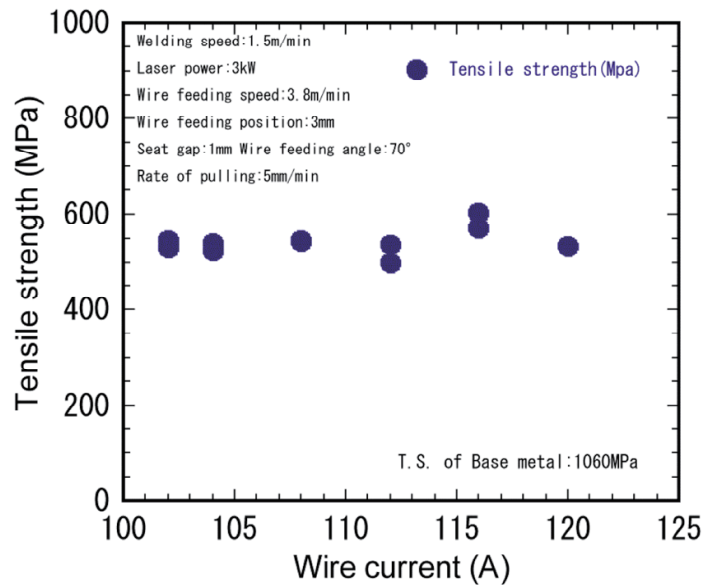

Fig. 8 Tensile shear strength of lap welded joints.

\section{Conclusions}

The hot-wire laser welding was proposed for the lap joint of the high tensile / ultra-high tensile strength sheets with a wide gap, and its welding phenomenon was investigated precisely by using a high-speed camera, then the optimum welding conditions was obtained in this study. The obtained conclusions are as follows.

(1) The hot-wire laser system makes the penetrated hole and the molten pool by laser irradiation firstly, and then filler wire heated up through energization fills the penetrated hole in the proposed hot-wire laser lap welding method. The optimum conditions for the $1 \mathrm{~mm}$ gap are $1.5 \mathrm{~mm}$ of the spot diameter, 3 $\mathrm{mm}$ of the wire feeding position, $70^{\circ}$ of the wire feeding angle and $102 \sim 116 \mathrm{~A}$ of the wire current for $3 \mathrm{~kW}$ of laser power, 1.5 $\mathrm{m} / \mathrm{min}$ of the welding speed, $3.8 \mathrm{~m} / \mathrm{min}$ of the wire feeding speed, $1 \mathrm{~mm}$ of the base sheet thickness and $1.2 \mathrm{~mm}$ of the filler wire diameter.
(2) The laser spot diameter and the welding speed which make the molten pool having a little lager width than the filler wire diameter, the wire feeding position and angle which is the anterior region of the molten pool crated posterior to the penetrated hole, and the wire current which makes wire melting in the region from the upper sheet surface to the gap between the lapped sheets are necessary for the stable welding phenomenon and sound bead creation.

(3) The stable and high tensile shear strength $(500 \sim 600 \mathrm{MPa})$ can be obtained in the wide wire current region $(102 \sim 120$ A) using the optimum welding conditions based on the above investigation.

\section{Reference}

1) Y. Daisho: Perspective on Future Motor Vehicle Technologies Associated with Environment and Energy, IATSS Review, 33-3 (2008), 51-56

2) M. Takahashi: Development of High Strength Steels for Automobiles, Nippon Steel Technical Report, 378 (2003), 2-6.

3) E. Nakanishi: High Strength Steel and Welding Technologies in Body Assemblies, J. JWS, 75-6 (2006), 71-73.

4) T. Konishi: Welding and Joining of Car Body, J. JWS, 74-8 (2005), 6-9.

5) K. Loeffler: The Latest Applied Technology of the Auto Industry in Europe on the Example of the Body in White Applications of the Volkswagen Golf V, J. JWS, 73-8 (2004), 15-18.

6) M. Ono, Y. Shinbo, A. Yoshitake and M. Ohmura: Laser-Arc Hybrid Welding of Thin Steel Sheets, Q. J. JWS, 21-4 (2003), 515-521.

7) M. Uchihara: Joining Technologies for Automotive Steel Sheets, J. JWS, 77-8 (2008), 10-17.

8) J.F. Saenger and A.F. Manz: High Deposition Gas Tungsten Arc Welding, Weld. J., 47-5 (1968), 386-393.

9) M. Yamamoto, K. Shinozaki, T. Myoga, T. Kanazawa and H. Arashin: Development of Ultra-High-Speed GTA Welding Process, IIW Doc. XII-1927-07 (2007).

10) K. Shinozaki, M. Yamamoto, Y. Nagamitsu, T. Uchida, K. Mitsuhata, T. Kanazawa and H. Arashin: Melting Phenomenon during Ultra-High-Speed GTA Welding Method using Pulse-Heated Hot-Wire, Quar. J. JWS, 27 (2009), 22-26.

11) K. Shinozaki, M. Yamamoto, K. Mitsuhata, T. Nagashima, T. Kanazawa and H. Arashin: Bead Formation and Wire Temperature Distribution during Ultra-high-speed GTA Welding Using Pulse-heated Hot-wire, IIW Doc. XII-1964-09 (2009). 